\title{
Prevalence of crowding, boarding and staffing levels in Swedish emergency departments - a National Cross Sectional Study
}

\author{
Jens Wretborn ${ }^{1,2}$, Joakim Henricson ${ }^{1,3}$, Ulf Ekelund ${ }^{2}$ and Daniel B. Wilhelms ${ }^{1,3^{*}}$ (D)
}

\begin{abstract}
Background: Emergency Department (ED) crowding occurs when demand for care exceeds the available resources. Crowding has been associated with decreased quality of care and increased mortality, but the prevalence on a national level is unknown in most countries.

Method: We performed a national, cross-sectional study on staffing levels, staff workload, occupancy rate and patients waiting for an in-hospital bed (boarding) at five time points during $24 \mathrm{~h}$ in Swedish EDs.

Results: Complete data were collected from 37 (51\% of all) EDs in Sweden. High occupancy rate indicated crowding at 12 hospitals (37.5\%) at 31 out of $170(18.2 \%)$ time points. Mean workload (measured on a scale from 1, no workload to 6 , very high workload) was moderate at $2.65( \pm 1.25)$. Boarding was more prevalent in academic EDs than rural EDs (median 3 vs 0). There were an average of 2.6, 4.6 and 3.2 patients per registered nurse, enrolled nurse and physician, respectively.

Conclusion: ED crowding based on occupancy rate was prevalent on a national level in Sweden and comparable with international data. Staff workload, boarding and patient to staff ratios were generally lower than previously described.
\end{abstract}

Keywords: Emergency department, Crowding, Boarding

\section{Background}

The emergency department (ED) is the nexus for patient inflow at a modern hospital. The combination of high acuity patients and frequent peaks in demand often results in crowding and a high workload for the staff $[1,2]$.

Crowding has been linked to increased inpatient mortality and decreased quality of care [3-6]. Many investigations have been conducted at single EDs or in local

* Correspondence: daniel.wilhelms@liu.se

'Department of Emergency Medicine, Local Health Care Services in Central Östergötland, Linköping, Sweden

${ }^{3}$ Department of Biomedical and Clinical Sciences, Linköping University, S58185, Linköping, Sweden

Full list of author information is available at the end of the article health care systems, with large variations in the extent of crowding, and nationwide data are lacking [6-8]. Patients waiting in the ED for an in-hospital bed, also known as boarding or access block, have been identified as an important factor for ED crowding [2] but prospective studies of the problems are scarce $[9,10]$.

Sweden, with a population of 10 million, has a universal publicly funded health care system granting emergency care with a small co-payment at 72 EDs spanning from small rural EDs to large urban academic EDs. Despite a long tradition of high-quality healthcare databases in Sweden, the emergency medicine register still

(c) The Author(s). 2020 Open Access This article is licensed under a Creative Commons Attribution 4.0 International License, which permits use, sharing, adaptation, distribution and reproduction in any medium or format, as long as you give appropriate credit to the original author(s) and the source, provide a link to the Creative Commons licence, and indicate if changes were made. The images or other third party material in this article are included in the article's Creative Commons licence, unless indicated otherwise in a credit line to the material. If material is not included in the article's Creative Commons licence and your intended use is not permitted by statutory regulation or exceeds the permitted use, you will need to obtain permission directly from the copyright holder. To view a copy of this licence, visit http://creativecommons.org/licenses/by/4.0/. The Creative Commons Public Domain Dedication waiver (http://creativecommons.org/publicdomain/zero/1.0/) applies to the data made available in this article, unless otherwise stated in a credit line to the data. 
lacks national coverage and includes limited data on crowding [11].

Crowding in Swedish EDs has previously been a limited problem [12], but news reports have raised the issue in recent years, and several research projects on the topic have been initiated [13]. Sweden lacks unified national information about ED attendances but based on government reports from 2010 and 2015, it is clear that ED attendances and waiting times have increased [14] Similar trends are seen in Denmark which has a comparable health care system [15]. With no proportional increase in hospital beds during the last 30 years, Sweden now has the fewest inpatient beds per capita of all OECD countries [16]. Based on the conceptual inputthroughput-output model [17], there is a clear risk of crowding given the increasing number of ED attendances and decreasing number of hospital beds, limiting capacity to admit patients.

Despite almost two decades of international research, there is no consensus on how to measure crowding, and several methods have proven reliable and valid $[5,18]$. In this study we chose to measure occupancy rate and staff workload to encompass different aspects of crowding [17]. Occupancy rate is a simple numeric variable that accounts for the core resource, an ED treatment bed. Staff perception of crowding or workload has been used to derive the International Crowding Metric in Emergency Departments (ICMED), National Emergency Department Overcrowding Score (NEDOCS) and Swedish Emergency Department Assessment of Patient Load (SEAL), but is less studied outside these scores [19-21]. Workload is subjective in nature, but has face validity as a measure of human resource utilisation and may complement occupancy rate at times when available treatment beds does not reflect crowding. An example could be a surge in high acuity patients at a period with low staffing, which will result in a high workload at a low occupancy rate.

We aimed to study the current levels of crowding at Swedish EDs by assessing patient attendance, occupancy rate, boarding as well as staff numbers and workload.

\section{Methods}

\section{Study design and population}

We conducted a cross sectional, multi-centre study during 24h on April 25th 2018. All Swedish EDs listed in the national healthcare institution registry were offered to participate by written invitation (e-mail) to the officially listed head of department. The written invitation was followed up by a telephone call. Participation was confirmed in writing by the department head. EDs were classified by their hospital status in Sweden (Academic, Community and Rural), where academic centres were the only centres with tertiary, highly specialised care (such as neurosurgery, cardiothoracic surgery, transplantations and advanced burn care).

\section{Data collection}

During the $24 \mathrm{~h}$ period, each ED collected data at five pre-specified time points (00:00, 06:00, 12:00, 18:00, 23: 59). A questionnaire was supplied by the research coordination centre and the method of data gathering was left to each ED. We did not collect information on the personnel gathering the data. Data included the number of registered ED patients, the number of patients waiting for an in-hospital bed (boarding), the number of enrolled nurses, registered nurses and physicians, occupancy rate and overall ED workload. Each ED also provided information on the annual and daily census in the previous year (2017) and the number of available treatment beds.

\section{Measurements and definitions}

We defined occupancy rate like McCarthy et al. [18] as the number of patients divided by the number of beds where basic care could be provided, excluding corridor spaces. An occupancy rate above 1.0 was set as the cutoff to indicate crowding. Workload was assessed on a graded Likert scale with anchors from 1 (very low workload) to 6 (very high workload). It was used as a measure of staff perception of crowding in the ED and a score of 4.5 or higher was considered to indicate crowding [20]. A boarding patient was defined as a patient with a decision for admission who was still present in the ED, regardless of the duration.

The EDs reported if the study period was representative in terms of workload and if there were any extraordinary events during the $24 \mathrm{~h}$ period. They also graded the supply of inpatient beds during the study period on a scale from 1 (good bed availability) to 10 (extreme bed shortage). Data was recorded prospectively on a paperbased report form by a senior staff member and subsequently submitted in a digital form to the study coordinator.

\section{Statistics}

Census was reported as median. Registered patients, staffing levels and workload were reported as means with standard deviations (SD). Boarding patients were reported as medians with interquartile range (IQR).

Correlations were assessed using ordinary leastsquares linear regression. To compare medians, the grand median for each group was calculated. A two by two table was created by classifying each value as above or below the grand median, and we then applied Fisher's exact test. Staffing ratios were compared using parametric ANOVA and post-hoc testing with t-test. Boarding was compared using Kruskal-Wallis test and post-hoc 
Mann-Whitney-U test. The Holm method was used to adjust for multiple comparisons [22].

Data was imported into Pandas dataframes (version 0.23.4, https://pandas.pydata.org/) [23] and analysed with computer scripts in the Python programming language (version 3.7.2, https://www.python.org) using the scipy scientific library (version 1.1, https://www. scipy.org/) [24, 25] and statsmodels (version 0.10, https://www.statsmodels.org) [26] for statistical calculations.

\section{Ethics}

This study was carried out in accordance with The Declaration of Helsinki [27]. This study was approved for all sites by the regional ethics review board in Linköping, Sweden (permit reference: 2018/50-31). Informed consent was waived since no identifiable personal data was collected.

\section{Results}

\section{Participating sites}

Fifty-five out of 72 eligible EDs accepted participation and 37 (51\%) delivered complete data for the number of patients and workload assessments (Fig. 1). Thirty-five (49\%) EDs reported complete staffing data for all time points. Five out of Sweden's 7 (71\%) university hospitals responded in the study. The geographic distribution of the responding EDs is shown in Fig. 2.

The median number of annual visits in the participating EDs were 35,000 (range 3300-102,000) with 15 (44\%) reporting more than 40,000 visits per year. The number of patients seen in the EDs during the $24 \mathrm{~h}$ period was not different compared to the daily census of the previous year (median 95 vs $93, p=1.00$ ).

\section{Registered patients and boarding}

The number of registered patients showed a diurnal pattern in most EDs with a median of 20 (IQR 14-41) patients present at 18:00 and 4 (IQR 2-6) patients at 06: 00. The number of patients boarding in the ED followed the same pattern (Fig. 3) and correlated modestly to the number of patients in the ED $\left(r^{2}=0.31\right)$. Boarding was more prevalent in academic EDs than rural EDs with a median boarding of 3 (IQR 1-4) and 0 (IQR 0-1) patients respectively $(p=0.008)$. There was no significant difference between urban EDs (median 1, IQ 0-2) and rural or academic EDs.

\section{Occupancy rate and workload}

Occupancy rate was greater than 1.0 on at least one occasion at 12 EDs (37.5\%) and on a total of 31 out of 170 (18.2\%) time points. Mean occupancy rate was higher in academic EDs compared to rural EDs (0.89 vs 0.45, difference $0.37,95 \% \mathrm{CI} 0.16-0.58, p<0.001)$ and for urban compared to rural EDs (0.54 vs 0.45 , difference $0.24,95 \% \mathrm{CI}$ $0.016-0.48, p=0.037$ ) but there was no significant difference between academic and urban centres $(p=0.45)$. Mean workload was $2.65( \pm 1.25)$ and as higher than 4.5 at 14 out of 170 time points (8.2\%). There was a moderate correlation between workload with occupancy rate $\left(r^{2}=\right.$ 0.36 ) and assessed workload showed a similar diurnal pattern as occupancy rate (Fig. 4).

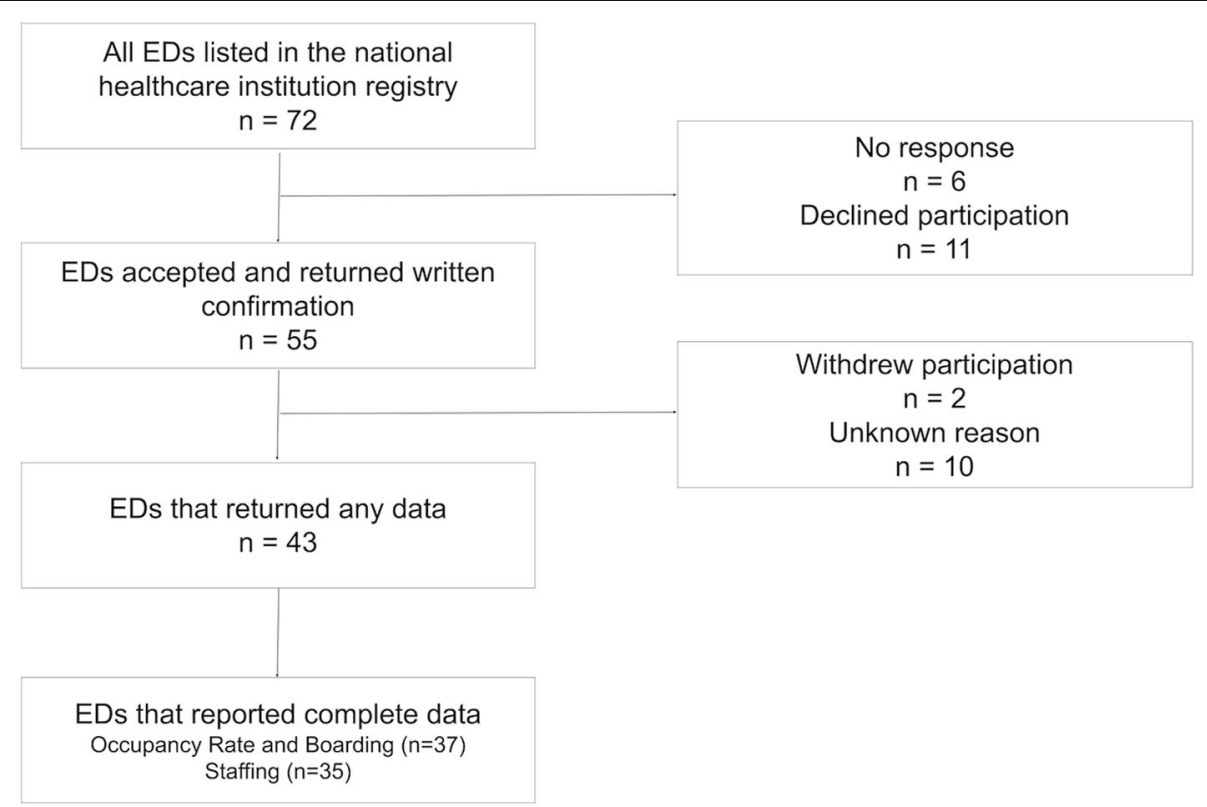

Fig. 1 Flowchart of participating sites 


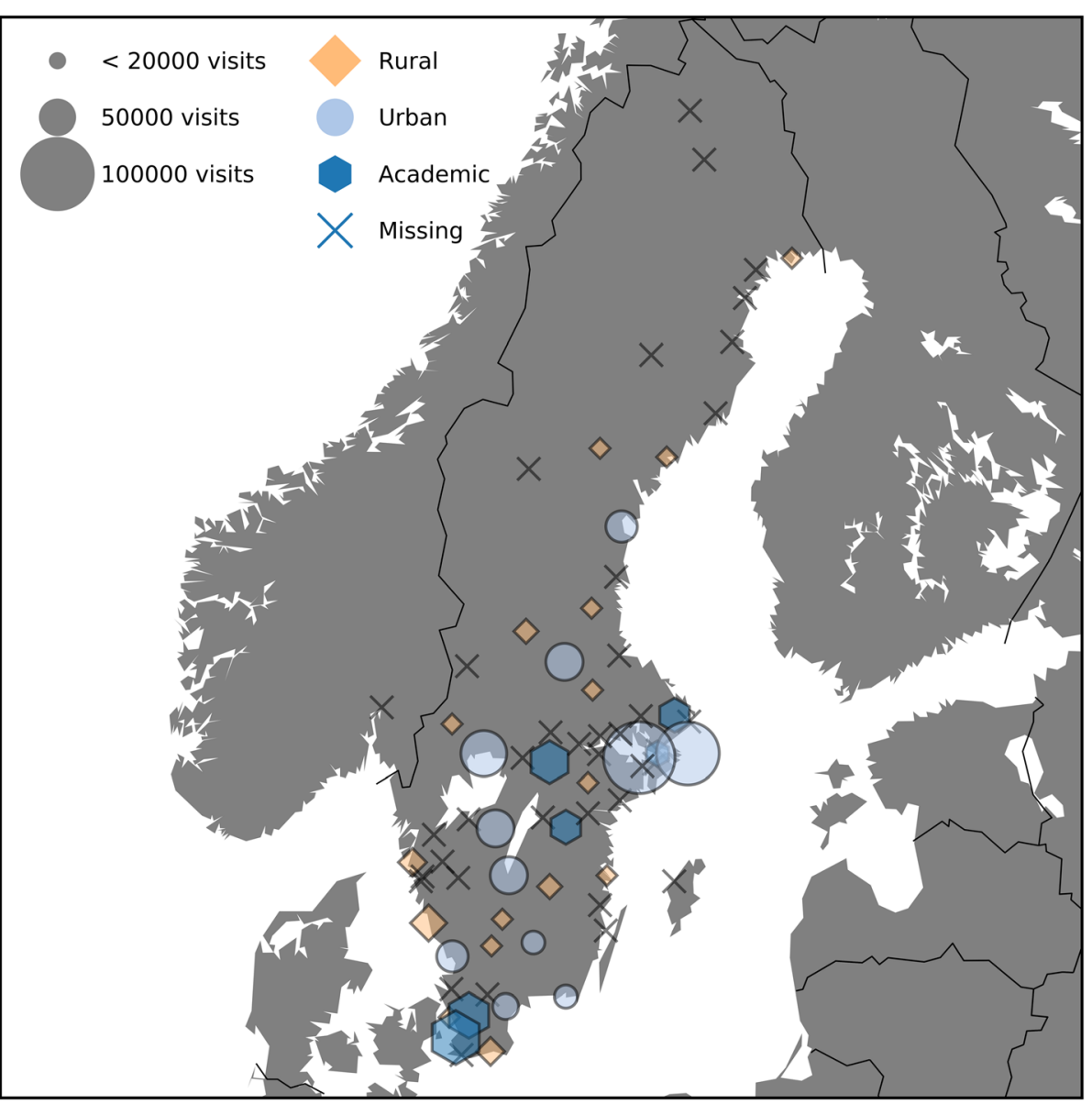

Fig. 2 Map of Sweden and geographic distribution of enrolled and missing EDs

\section{Staffing levels}

During the $24 \mathrm{~h}$ period, there was an average of $2.6( \pm$ 1.6) patients in the ED per registered nurse, $4.6( \pm 3.1)$ per enrolled nurse and $3.2( \pm 2.2)$ per physician, with little difference between time points except 06:00 which had lower ratios for all providers (Fig. 5). There were more patients per nurse in academic compared to rural EDs (4.4 vs $2.2, p=0.02)$ but not compared to urban EDs (4.4 vs 3.2, $p=0.08$ ) and no difference between rural and urban EDs (2.2 vs 3.2, $p=0.13$ ). There were more patients per physician at academic than rural EDs (4.4 vs 2.6, $p=0.01$ ), but there was no difference compared to urban EDs (4.4 vs 3.3, $p=0.13$ ) or between urban and rural EDs (3.3 vs 2.6, $p=0.13$ ).

\section{Non-clinical events}

There were no extraordinary incidents reported in any of the participating EDs' catchment areas. Four sites (11\%) reported hospital-specific disturbances. Of these, two were related to downtime in the electronic health records (EHRs) and two due to disturbances in other digital support systems (ancillary testing, registration and internal telephone system). None of these events were reported to affect the ED workflow.

\section{Discussion}

In this national cross-sectional study at Swedish EDs during $24 \mathrm{~h}$, we provide a snapshot of current Swedish ED crowding, boarding and staffing, which has never been done before. We observed that boarding was common and occupancy rates were generally high, primarily in academic EDs but also in urban EDs. On average, patient to staff ratios for nurses were on par with internationally reported levels (see below), but lower for physicians. There were more patients per staff at academic centres compared to rural hospitals. Workload was mostly perceived as low to moderate, which indicated limited staff problems related to crowding during the study period.

Occupancy rate correlated modestly with workload, which suggests that these may reflect different aspects of crowding. Workload was subjectively assessed by a single senior provider at each ED which limits the generalizability. However, subjective provider judgement 


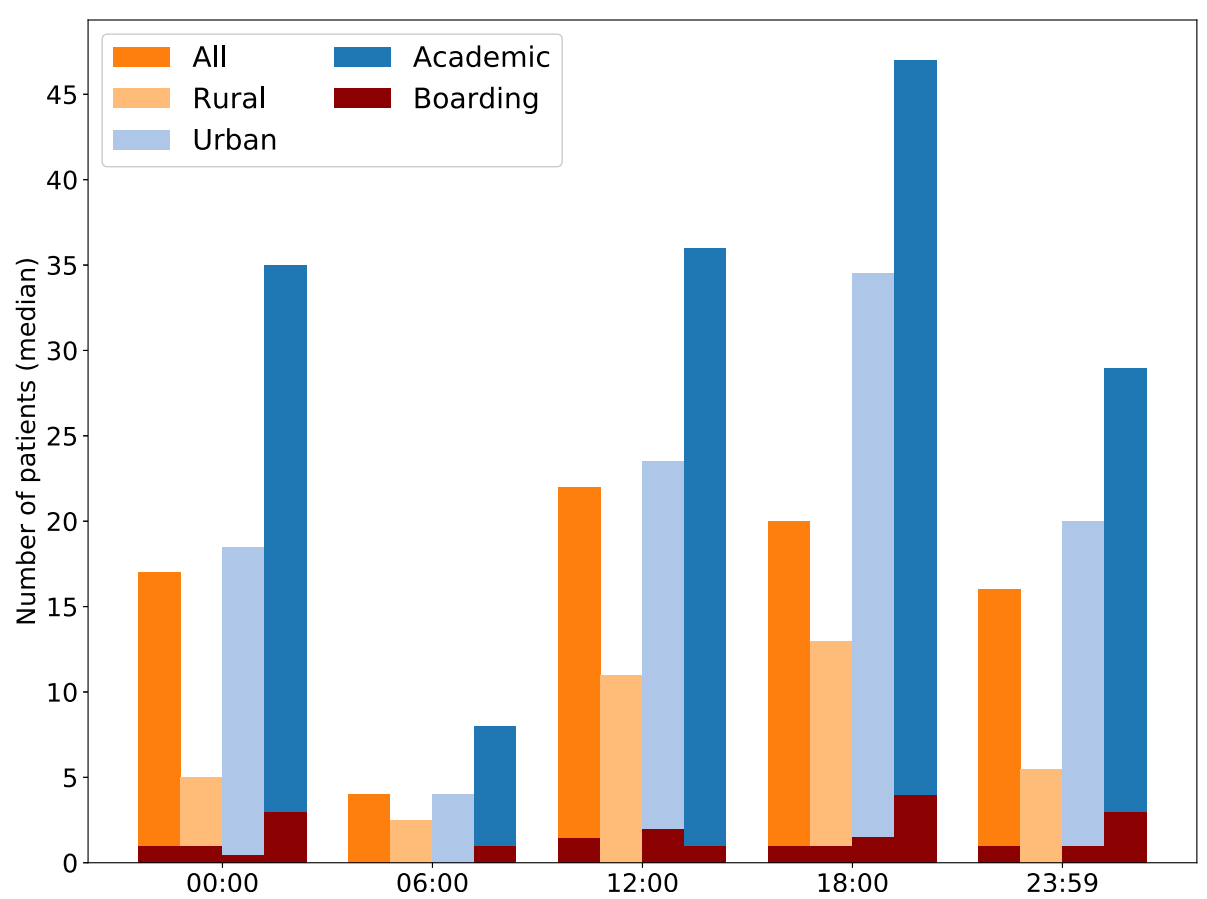

Fig. 3 Number of patients present and boarding for each hospital type at each time point

was used as an outcome measure in the original NEDOCS trial and this has been validated in several different settings $[19,28,29]$. Physicians' judgment has also proved to be equal or superior to structured decision support tools in many types of clinical decision-making ranging from imaging in trauma to the investigation in suspected pulmonary embolism [30].

Boarding was prevalent at many sites during this study. Generally however, boarding was reported as lower compared to the limited data from the United States (US)

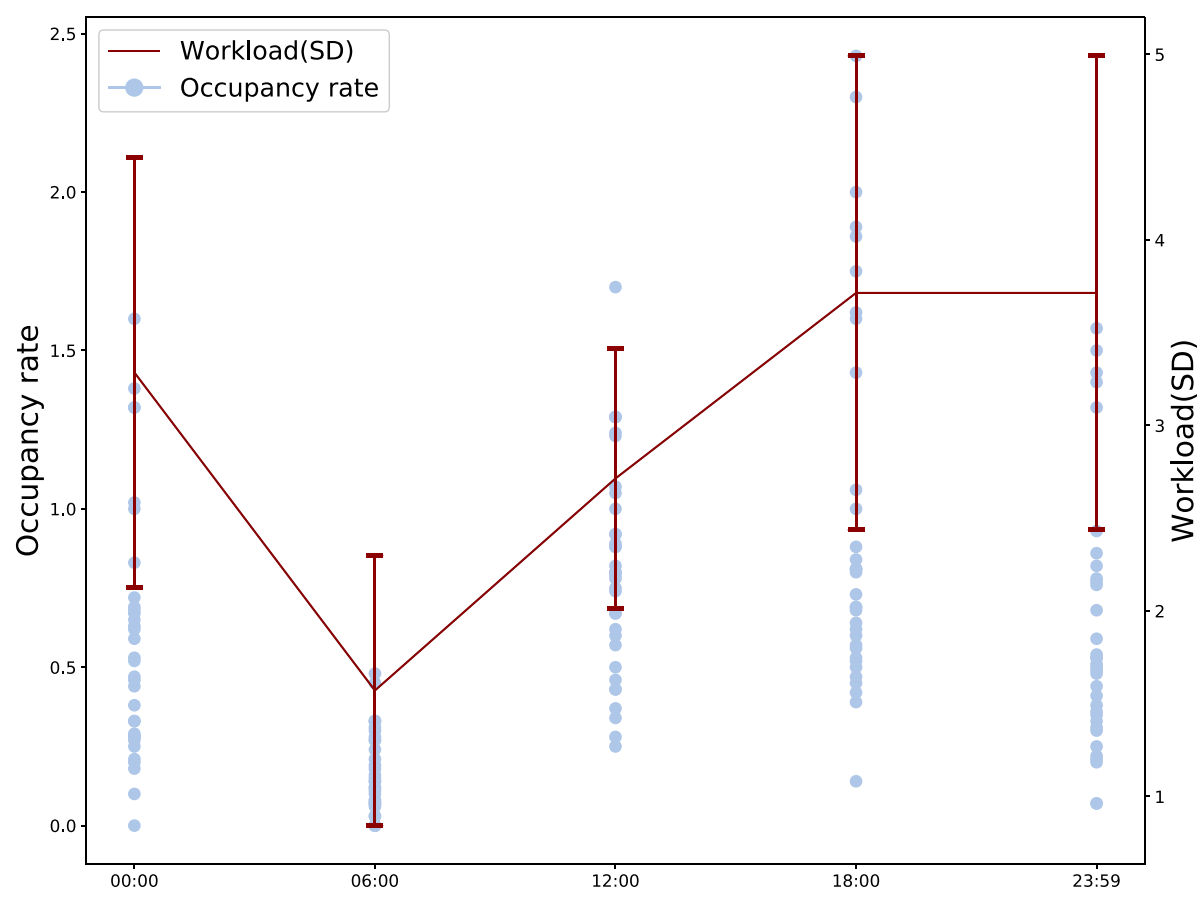

Fig. 4 Occupancy rate in relation to workload at each time point 


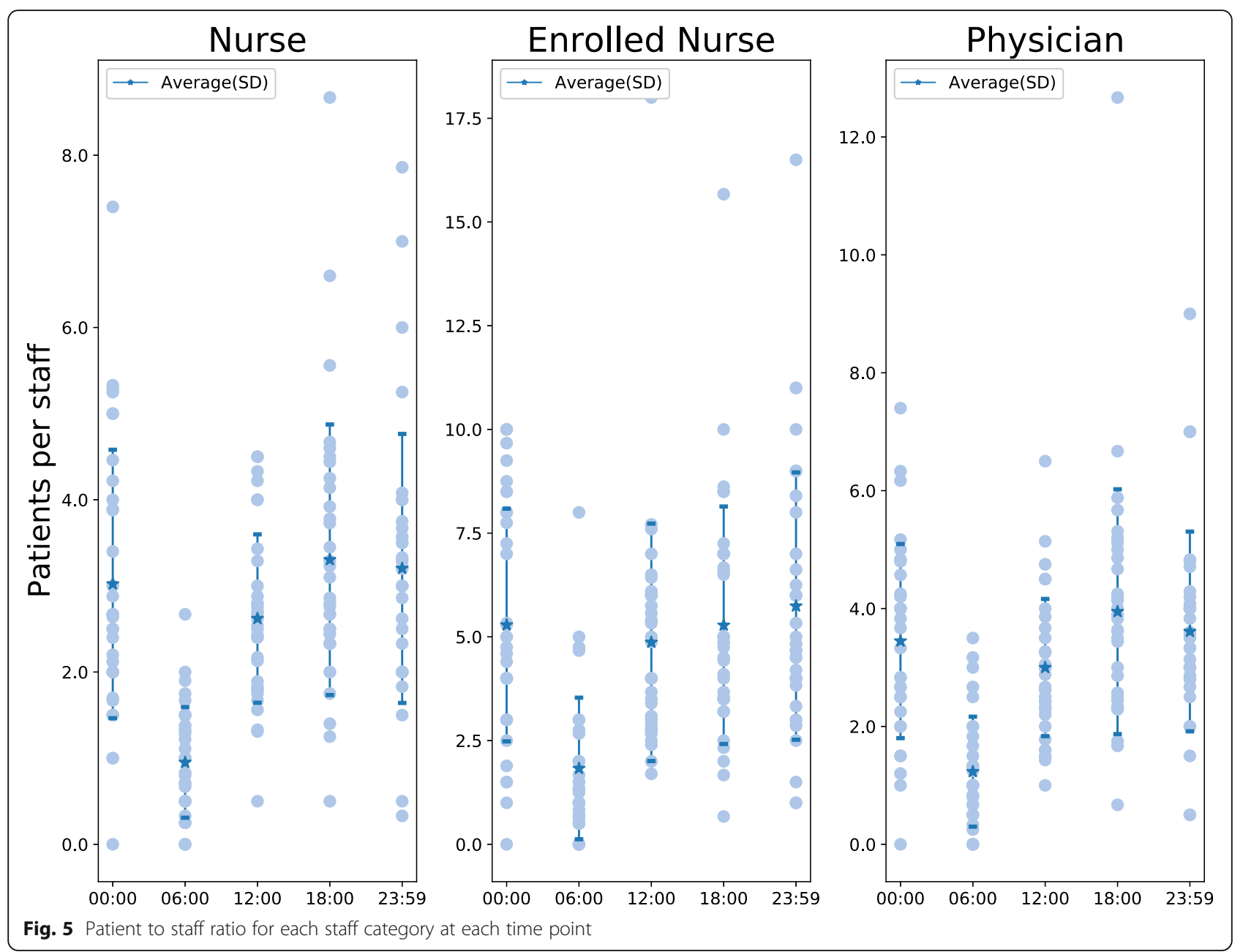

and Australia published so far. In a US cross sectional study of 89 EDs, $22 \%$ reported boarding patients and $73 \%$ of EDs had more than 2 patients boarding [9]. In a registry study of 139,509 ED visits in the US, median boarding time was 79 min [31]. In a study of 72 EDs in Australia, boarding ranged from 2 to 22 patients at two time points [10]. The difference in findings between the present and previous studies may be due to sampling errors or temporal effects, but it may also reflect possible differences in health care systems. Lack of inpatient beds is usually the basis for boarding patients in the ED. Since Sweden has fewer inpatient beds per capita than the US and Australia, our results support the claim that boarding may not be directly related to the number of hospital beds, but also to resource utilisation [32], both in single hospitals and in the system as a whole. It is important to note that our definition of boarding did not include a minimum waiting time after the decision to admit, and that we did not gather any further information regarding the admissions.

The staffing ratios were comparable at all study sites with most variation observed around midnight. This finding likely reflects that staffing is reduced at nighttime and that staffing ratios therefore become more dependent on the inflow of patients. We did not collect information about work shifts at each ED and cannot exclude that this may explain some of the variation in staff ratios. The emergency medicine literature provides little data for comparison, but Schneider et al. reported higher mean ratios for nurses (4.2) and physicians (9.7) in the US in 2003 [9]. The difference, particularly for physicians, may partly be due to different denominators since we registered all physicians irrespective of training level in this study. In Sweden, a majority of the current ED physicians are pre-interns, interns or residents and only a minority are on site consultants [14]. This may result in higher numbers of physicians working in the ED compared to the US, where EDs are primarily staffed by residents and consultants. There are no national recommendations for staffing ratios in Sweden but our results are within the four patients to one nurse ratio legislated in the US state of California [33].

During the $24 \mathrm{~h}$ period, four study sites (11\%) noted disturbances in the EHR or support systems, and this 
has previously been associated with increased ED crowding [34]. All EDs in Sweden use EHRs with a range of digital support systems for radiology, laboratory and other ancillary facilities. The reports may thus be an indicator of the fragility of complex digital systems to which ED providers must adapt. The lack of adverse events suggests mature systems with some resilience against unexpected downtime, leading to no serious disruption of clinical work. However, further studies will be needed to determine the frequency of EHR disturbances and their effects on emergency care.

\section{Limitations}

This was a cross sectional study during only $24 \mathrm{~h}$, and the generalisability of the results is therefore limited. There may be both seasonal differences in the demand and availability of healthcare resources. However, given the range of EDs both in size and geographic location, we believe that the results are a representative snapshot of the ED situation on a national level in Sweden.

The response rate was $51 \%$ among the eligible EDs regarding patient and crowding data, which is quite high compared to similar studies. Again, generalisability was most likely increased by the wide range of ED size and location. However, the fact that so many EDs chose to not participate emphasizes the need for mandatory and public reporting of this type of information for all EDs.

\section{Conclusion}

Based on this cross sectional study during $24 \mathrm{~h}$ in 37 EDs, crowding as measured by occupancy rate and ED boarding is prevalent in Sweden. Occupancy rates were comparable with international data, whereas boarding and patient to staff ratios were lower than reported in the limited existing literature. In contrast to occupancy rate and boarding, patient to staff ratios and perceived workload did not suggest high levels of crowding. These observations highlight the importance of measuring different aspects of the complex entity of ED crowding.

\section{Abbreviations}

ED: Emergency Department; EHR: Electronic Health Record; ICMED: International Crowding Metric in Emergency Department: IQR: Interquartile Range; NEDOCS: National Emergency Department Overcrowding Score; SEAL: Swedish Emergency Department Assessment of Patient Load; SD: Standard Deviation; US: United States

\section{Acknowledgements}

The authors like to acknowledge research nurse Erika Hörlin for her assistance with data collection.

\section{Authors' contributions}

DBW conceived the study and obtained the ethical permit. DBW and JW designed the trial. DBW and JH coordinated data collection. JW managed the data, with the assistance of DBW, JH and UE. DBW and UE obtained the research funding. DBW supervised the conduct of the trial. DBW and JW drafted the manuscript. All authors contributed substantially to its revision. JW takes responsibility for the paper as a whole. All authors have read and approved the manuscript.

\section{Funding}

This work was supported by two grants from Region Östergötland to author DBW (LIO-532001 and LIO-700271), and from Region Skåne to author UE. The funding bodies had no role or influence over any aspect of this study. Open access funding provided by Linköping University.

\section{Availability of data and materials}

The datasets generated during and/or analysed during the current study are available from the corresponding author on reasonable request.

\section{Ethics approval and consent to participate}

This study was approved for all sites by the regional ethics review board in Linköping, Sweden (permit reference: 2018/50-31). Informed consent was waived since no identifiable personal data was collected.

Consent for publication

Not applicable.

\section{Competing interests}

The authors declare no competing interests.

\section{Author details}

${ }^{1}$ Department of Emergency Medicine, Local Health Care Services in Central Östergötland, Linköping, Sweden. 'Department of Clinical Sciences Lund, Emergency Medicine, Faculty of Medicine, Lund University, Lund, Sweden. ${ }^{3}$ Department of Biomedical and Clinical Sciences, Linköping University, S58185, Linköping, Sweden.

Received: 17 January 2020 Accepted: 28 May 2020

Published online: 18 June 2020

\section{References}

1. Johnston A, Abraham L, Greenslade J, Thom O, Carlstrom E, Wallis M, et al. Review article: staff perception of the emergency department working environment: integrative review of the literature: ED staff perception of working environment. Emerg Med Australas 2016;28:7-26. doi:10.1111/17426723.12522.

2. Hoot NR, Aronsky D. Systematic review of emergency department crowding: causes, effects, and solutions. Ann Emerg Med 2008;52:126-136. doi:10.1016/j.annemergmed.2008.03.014

3. Sun BC, Hsia RY, Weiss RE, Zingmond D, Liang L-J, Han W, et al.. Effect of emergency department crowding on outcomes of admitted patients. Ann Emerg Med. 2013;61:605-611.e6. doi:10.1016/j.annemergmed.2012.10.026.

4. Gabayan GZ, Derose SF, Chiu VY, Yiu SC, Sarkisian CA, Jones JP, et al. Emergency Department Crowding and Outcomes After Emergency Department Discharge. Ann Emerg Med. 2015;66:483-92 e5. doi:10.1016/j. annemergmed.2015.04.009..

5. Stang AS, Crotts J, Johnson DW, Hartling L, Guttmann A. Crowding measures associated with the quality of emergency department care: a systematic review. Acad Emerg Med 2015;22:643-656. doi:10.1111/acem. 12682.

6. Bernstein SL, Aronsky D, Duseja R, Epstein S, Handel D, Hwang U, et al. The effect of emergency department crowding on clinically oriented outcomes. Acad Emerg Med 2009;16:1-10. doi:10.1111/j.1553-2712.2008.00295.x.

7. Rahmani F, Rezazadeh F, Ala A, Soleimanpour M, Mehdizadeh Esfanjani R, Soleimanpour $\mathrm{H}$. Evaluation of overcrowding of emergency Department in Imam Reza Hospital in 2015 by implementing 2 scales: NEDOCS and EDWIN. Iran Red Crescent Med J 2017;19. doi:10.5812/ircmj.15609.

8. Wang Z, Xiong X, Wang S, Yan J, Springer M, Dellinger RP. Causes of emergency department overcrowding and blockage of access to critical Services in Beijing: a 2-year study. J Emerg Med 2018;54:665-673. doi:10. 1016/j.jemermed.2018.02.009.

9. Schneider SM, Gallery ME, Schafermeyer R, Zwemer FL. Emergency department crowding: a point in time. Ann Emerg Med 2003;42:167-172. https://www.ncbi.n/m.nih.gov/pubmed/12883503.

10. Richardson DB, Mountain D. Myths versus facts in emergency department overcrowding and hospital access block. Med J Aust 2009;190:369-374. https://www.ncbi.n/m.nih.gov/pubmed/19351311.

11. Ekelund $U$, Kurland L, Eklund F, Torkki $P$, Letterstål $A$, Lindmarker $P$, et al. Patient throughput times and inflow patterns in. Scand J Trauma Resusc Emerg Med 2011;19:37. http://www.sjtrem.com/content/19/1/37. 
12. Pines JM, Hilton JA, Weber EJ, Alkemade AJ, Al Shabanah H, Anderson PD, et al. International Perspectives on emergency department crowding: International Perspectives On Ed Crowding. Acad Emerg Med 2011;18:13581370. doi:10.1111/j.1553-2712.2011.01235.x.

13. Berg LM, Ehrenberg A, Florin J, Östergren J, Discacciati A, Göransson KE. Associations between crowding and ten-day mortality among patients allocated lower triage acuity levels without need of acute hospital care on departure from the emergency department. Ann Emerg Med 2019. doi:10. 1016/j.annemergmed.2019.04.012.

14. Ruge T, Granberg M, Helmers SB. Väntetider och patientflöden på akutmottagningar - Rapport februari 2017. 2017. https://www. socialstyrelsen.se/globalassets/sharepoint-dokument/artikelkatalog/ovrigt/2 017-2-16.pdf. Accessed 22 Mar 2019.

15. Fløjstrup M, Bogh SB, Henriksen DP, Bech M, Johnsen SP, Brabrand M. Increasing emergency hospital activity in Denmark, 2005-2016: a nationwide descriptive study. BMJ Open 2020;10:e031409. doi:10.1136/bmjopen-2019031409

16. OECD. Health at a Glance 2017. 2017. doi:10.1787/health_glance-2017-en.

17. Asplin BR, Magid DJ, Rhodes KV, Solberg LI, Lurie N, Camargo CA Jr. A conceptual model of emergency department crowding. Ann Emerg Med 2003:42:173-180. doi:10.1067/mem.2003.302.

18. McCarthy ML, Aronsky D, Jones ID, Miner JR, Band RA, Baren JM, et al. The Emergency Department Occupancy Rate: A Simple Measure of Emergency Department Crowding? Ann Emerg Med. 2008;51:15-24.e2. doi:10.1016/j. annemergmed.2007.09.003

19. Weiss SJ, Derlet R, Arndahl J, Ernst AA, Richards J, Fernández-Frackelton M, et al. Estimating the degree of emergency department overcrowding in academic medical centers: results of the national ED overcrowding study (NEDOCS). Acad Emerg Med 2004;11:38-50. doi:10.1197/S10696563(03)00583-9.

20. Wretborn J, Khoshnood A, Wieloch M, Ekelund U. Skåne emergency department assessment of patient load (SEAL)-a model to estimate crowding based on workload in Swedish emergency departments. PLoS One 2015;10:e0130020. doi:10.1371/journal.pone.0130020.

21. Boyle A, Coleman J, Sultan Y, Dhakshinamoorthy V, O'Keeffe J, Raut P, et al. Initial validation of the international crowding measure in emergency departments (ICMED) to measure emergency department crowding. Emerg Med J 2015;32:105-108. doi:10.1136/emermed-2013-202849.

22. Holm S. A simple sequentially Rejective multiple test procedure. Scand Stat Theory Appl 1979;6:65-70. http://www.jstor.org/stable/4615733..

23. McKinney W. Data structures for statistical computing in python. In: Proceedings of the 9th Python in Science Conference. 2010. p. 51-6. https://doi.org/10.25080/Majora-92bf1922-00a.

24. Virtanen P, Gommers R, Oliphant TE, Haberland M, Reddy T, Cournapeau D, et al. SciPy 1.0: fundamental algorithms for scientific computing in Python. Nat Methods. 2020;17:261-72. https://doi.org/10.1038/s41592-019-0686-2.

25. Millman KJ, Aivazis M. Python for scientists and engineers. Comput Sci Eng 2011;13:9-12. doi:10.1109/MCSE.2011.36.

26. Seabold S, Perktold J. Statsmodels: Econometric and statistical modeling with python. In: 9th Python in Science Conference. 2010.

27. World Medical Association. World medical association declaration of Helsinki: ethical principles for medical research involving human subjects. JAMA. 2013;310:2191-2194. doi:10.1001/jama.2013.281053..

28. Jones SS, Allen TL, Flottemesch TJ, Welch SJ. An independent evaluation of four quantitative emergency department crowding scales. Acad Emerg Med 2006;13:1204-1211. doi:10.1197/j.aem.2006.05.021.

29. Boyle A, Abel G, Raut P, Austin R, Dhakshinamoorthy V, Ayyamuthu R, et al. Comparison of the international crowding measure in emergency departments (ICMED) and the National Emergency Department Overcrowding Score (NEDOCS) to measure emergency department crowding: pilot study. Emerg Med J 2016;33:307-312. doi:10.1136/emermed2014-203616.

30. Schriger DL, Elder JW, Cooper RJ. Structured clinical decision aids are seldom compared with subjective physician judgment, and are seldom superior. Ann Emerg Med 2017. doi:10.1016/j.annemergmed.2016.12.004..

31. Pitts SR, Vaughns FL, Gautreau MA, Cogdell MW, Meisel Z. A cross-sectional study of emergency department boarding practices in the United States. Acad Emerg Med 2014;21:497-503. doi:10.1111/acem.12375.

32. Chang AM, Cohen DJ, Lin A, Augustine J, Handel DA, Howell E, et al. Hospital strategies for reducing emergency department crowding: a mixed-methods study. Ann Emerg Med 2017. doi:10.1016/j.annemergmed.2017.07.022.
33. Chan TC, Killeen JP, Vilke GM, Marshall JB, Castillo EM. Effect of mandated nurse-patient ratios on patient wait time and care time in the emergency department. Acad Emerg Med 2010;17:545-552. doi:10.1111/j.1553-2712. 2010.00727.x.

34. Wretborn J, Ekelund U, Wilhelms DB. Emergency department workload and crowding during a major electronic health record breakdown. Front Public Health 2019;7:267. doi:10.3389/fpubh.2019.00267.

\section{Publisher's Note}

Springer Nature remains neutral with regard to jurisdictional claims in published maps and institutional affiliations.
Ready to submit your research? Choose BMC and benefit from:

- fast, convenient online submission

- thorough peer review by experienced researchers in your field

- rapid publication on acceptance

- support for research data, including large and complex data types

- gold Open Access which fosters wider collaboration and increased citations

- maximum visibility for your research: over $100 \mathrm{M}$ website views per year

At BMC, research is always in progress.

Learn more biomedcentral.com/submissions 